\title{
PHILOSOPHICAL APPROACH TO THE CLASSIFICATION OF NEEDS OF A HUMAN BEING IN $21^{\text {ST }}$ CENTURY
}

\section{Yarochenko Yanina ${ }^{1}$}

DOI: https://doi.org/10.30525/978-9934-571-89-3_50

Philosophy has always shown interest to a human being as himself, to his existence and self-knowledge. All philosophical questions, as to Kant, are reduced to one: "What is a Person?" A human being, an individual, a person, as contemporary worldview categories of research in historical-philosophical discourse of the $21^{\text {st }}$ century, were covered in philosophical anthropology and existentialism. A human being is studied as a self-sufficient part of culture and society, as a multi-layered, thinking, creative subject, and his life - as a field of self-identification, self-awareness, and self-actualization.

It is advisable to apply a hierarchical method for classifying the needs of the $21^{\text {st }}$ century person, which involves the sequential division of the set of needs of the

\footnotetext{
${ }^{1}$ National Pedagogical Drahomanov University, Ukraine
} 
modern human being into subordinate classification groups, and classify the needs of a person at the level of the Individual - the Individuality - the Personality.

Individual is a separate representative of the human race, which has unique natural and social qualities [3, p. 435]. As individuals, people differ from each other not only by morphological features (such as height, body constitution and color of eyes), but also psychological properties (abilities, temperament, emotionality). From the standpoint of sociology, the individual is a characteristic of a man as a separate representative of the biological species of Nomo Sapiens. At this level, according to the developed classification, it is expedient to allocate biological needs in: oxygen, water, food and energy, physiological needs, motion, relaxation and sleep, hygiene, clothing and housing, sexual need, gender needs.

Undoubtedly, a person is physically immersed in the physical world, interacts with it, uses it for his own purposes, or in other words, a person needs the physical properties of the environment, or just biological necessities. Some of these necessities are vital: oxygen, water, food and energy, etc. However, human life is not determined by this necessity, since these needs serve only as an opportunity to live. Everything in the world and society is defined by people as opportunities. So, the need for food is an opportunity to survive, to prolong life, which "may or may not be". And only the human being may understand it. And to meet this urgent need for life, a person is also treated as an opportunity: it more or less freely selects ways of satisfying it, which is always only possible.

Carl Jung, a Swiss psychiatrist and psychoanalyst who founded analytical psychology, stated that the goal of life is individuation, the process of coming to know, giving expression to, and harmonizing the various components of the psyche. From the foregoing it follows that a human being is already an individual by the fact of his birth. Initially, the he does not have the individuality, but can acquire it later.

Individuality is a combination of characteristic features and properties that distinguish one individual from another. It manifests itself in a complex of psychological peculiarities such as temperament, character, specific habits, dominant admiration, quality of cognitive activity, etc. When it comes to individuality, it is not enough to indicate only the unique features of a person, it is necessary to characterize the original relationship between the above categories. An important criterion in the description of human personality is the qualitative and quantitative analysis of her abilities. Intellectual capacity are a special feature of the psyche that determines the ability of a person to productively acquire knowledge and skills.

However, intellectual capabilities is not a fact of knowledge, but a prerequisite for their easy assimilation in an interesting field for a person to which she has an innate and/or acquired tendency. There are no two people with full coincidence of the configuration of emotional and psychological properties. The uniqueness of the personality is precisely by individuality. A distinct personality can be attributed to both talent in the intellectual and creative spheres, or intellectual talent in the field of interest. "Hidden", less noticeable to people, but important for man's manifestation of individuality, is a developed volitional principle that provides for a personal self- 
control, endurance, prudence, etc. According to developed classification at the level of individuality, social needs are: love, unconditional love, respect, and freedom.

According to Maslow's hierarchy of needs, when the needs for safety and for physiological well-being are satisfied, the next class of needs for love, affection and belongingness can emerge. Abraham Maslow states that people seek to overcome feelings of loneliness and alienation. This involves both giving and receiving love, affection and the sense of belonging [2, p. 375].

Also, according to author's opinion, at the levels of individual-individuality the existential-prestigious needs are emerging, such as: safety, psychological safety and personal comfort. All existential-prestigious needs can be divided into basic necessities, objects of long-time use and luxury goods. For example, the primary necessity is water (running water), long-term use - filtered water, luxury - structured mountain premium class water. However, such a division is unstable: something that was considered a luxury item a few years ago can now be a matter of necessity or vice versa. In addition, due to various abundance, what is an object of luxury for one person, is a matter of necessity - for another one.

Personality is a human individual who is a subject of conscious activity, possessing a set of socially significant features, properties and qualities that he implements in social life. In a history, the concept of personality based on deepen knowledge about human being has changed. According to modern philosophers, a person is a social individual who has socially significant features that form a stable system [3, p. 436]. Consequently, in my opinion, a human being can be called the person when he has a certain autonomy and self-sufficiency in his actions, behavior and way of thinking. The level of personal development can be figured out by the variety of needs, by their nature, the ways of their origin and satisfaction. Thus, at this level the personality tend to spiritual needs in: knowledge, self-knowledge, creativity and creation, esthetical needs, self- improvement; the sense of life; self-actualization; transcendental needs.

The spiritual need for cognition of "higher" is felt by person's foreseeing and preaware of the mystery of eternity, destiny, death, meeting with the Highest, etc. This premonition stands in the special states of the human spirit, such as grief, horror, meditation, inspiration, ecstasy. Living in the $21^{\text {st }}$ century, a person tends to feel the need for a transition to "higher" (transcendence) in such cognitive relationships with the world as family, gender. Consequently, as to Vladimir Zavalnyuk, contrary to the prevailing two-dimensional vision of a person as a being having a body and a psyche, it is worth recognizing the third "sphere", the third human dimension - spirituality, or just the spirit [5, p. 70].

Breaking his own limits, a person seems to immerse himself in the sphere of "spirit", where the main definition of the spiritual being is existential independence from the organic - freedom from coercion and pressure. A highly developed personality is primarily a person with deep intelligent needs, with a high culture of consumption. During the personal life, new needs are formed, they become more and more widen, their structure changes. As there is a constant and qualitative growth of needs, author agreed with the thought that the human needs are endless. But for a 
$21^{\text {st }}$ century human being, the inherent feature is the desire for existential-spiritual needs in balanced and harmonic adequacies at all levels: the individual - the individuality - the personality. So, at the individual level, there is a need for symbiosis of biological needs; at the level of individuality - the need for synergy of social needs; at the level of personality - the need for introspection of spiritual needs.

At any given time, under "favorable" circumstances, any of the above mentioned needs can be transformed into quasi-needs. In author's opinion, quasi-needs (mistakes, foolish, imaginary) are the needs for involution and disintegration. The satisfaction of which leads to physical and spiritual degradation of the human being, as well as harm to nature and society. Also, quasi-needs are called needs that go beyond the limits of reasonable standards, and take hypertrophied and/or perverted forms. For example: at the biological level, the need for food can be transformed into gluttony; at the social level, the need for love can be transformed into hate, and tenderness into sadism; at the spiritual level, the need for selfawareness can be transformed into self-digging. The phenomenon of quasi-needs of a person reflects the duality of human existence in a philosophical context: duality of needs - duality of being.

At the present stage of the evolution of philosophical discourse, in addition to the classical categories, such as "human being", "society", "existence", and others, further explication of human needs have been gained. Taking into account the trends of society in the $21^{\text {st }}$ century, the structuring of human needs has philosophical approach. A modern human being tends to move towards existential-spiritual needs, but if his biological, social and spiritual needs are not satisfied at least on the basic level, this movement is significantly slowed down. The modern classification of needs reflects the ideal way of personal development and focuses on the possible manifestation of quasi-needs that have the potential to affect destructively to human existence.

\section{References:}

1. Lombo, J. A., \& Russo, F. (2017). Philosophical Anthropology An Introduction. Midwest Theological Forum: Digital Edition, 280. doi: 10.1515/9783110321821.7

2. Maslow, A. (1943). Preface to Motivation Theory. Psychosomatic Medicine. 5(1):85-92, 375. doi: 10.1097/00006842-194301000-00012

3. Nadolnyy, I. F., Andrushchenko, V. P., Boychenko, I. V. \& Rozumnyy, V. P. (1997). Philosophy: Textbook. - Kyiv: Vikar, 435, 436.

4. Ricoeur, P. (2016). Philosophical Anthropology: $1^{\text {st }}$ Edition. Polity Press, 304.

5. Zavalniuk, V. V. (2009). Anthropological dimension of spheres of human existence. Scientific works of the Odessa National Law Academy, 64, 70. 